\title{
Hubungan Faktor Internal dengan Perilaku Seksual Berisiko pada Remaja (Analisis SKAP Provinsi Bengkulu 2019)
}

\author{
Betty Yosephin Simanjuntak ${ }^{1}$, Desri Suryani², Meriwati³, Agus Supardi, \\ Frensi Riastuti ${ }^{5}$ \\ 1,2,3Poltekkes Kemenkes Bengkulu, Jurusan gizi \\ 4,5Badan Kependudukan dan Keluarga Berencana Nasional Propinsi Bengkulu \\ patricknmom@yahoo.co.id ${ }^{1}$
}

\author{
Diajukan 14 Mei 2021 Diperbaiki 28 November 2021 Diterima 30 November 2021

\section{ABSTRAK}

Latar Belakang: Perilaku seksual berisiko pada remaja semakin mengkhawatirkan, biasanya diawali dengan meraba, berpegang tangan hingga berciuman. Ada beberapa faktor yang memungkinkan terjadinya perilaku seksual ini baik internal maupun eksternal.

Tujuan: Menganalisis faktor internal yang berkaitan dengan perilaku seksual berisiko remaja di Provinsi Bengkulu.

Metode: Penelitian bersifat kuantitatif dengan menggunakan pendekatan cross-sectional pada 301 keluarga yang memiliki remaja berusia 10-24 tahun di wilayah Provinsi Bengkulu. Analisis data dilakukan secara deskriptif (univariat) dan bivariat dengan menggunakan uji chi square.

Hasil: Perilaku seksual berisiko pada remaja diawali dengan adanya perilaku berpegangan tangan $(83,4 \%)$, berpelukan $(34,2 \%)$, ciuman bibir $(15,6 \%)$, dan meraba/merangsang $(3,3 \%)$, sebagian besar berusia 15-19 tahun dengan tingkat pendidikan SLTA, serta mayoritas tinggal di pedesaan. Faktor risiko umur berpengaruh terhadap perilaku berpegangan tangan $(p=0,018)$, berpelukan $(p<0,001)$ dan ciuman bibir $(p<0,001)$. Jenis kelamin berpengaruh terhadap perilaku berpelukan $(p<0,001)$, ciuman bibir $(p=0,010)$ dan meraba atau merangsang $(p=0,008)$. Pendidikan berpengaruh terhadap perilaku berpegangan tangan $(\mathrm{p}<0,001)$ dan ciuman bibir $(\mathrm{p}=0,010)$, sedangkan faktor risiko tempat tinggal diketahui berpengaruh terhadap perilaku ciuman bibir $(\mathrm{p}=0,030)$.

Kesimpulan: Umur, jenis kelamin, tingkat pendidikan serta tempat tinggal menjadi faktor risiko terjadinya perilaku seksual remaja khususnya berpegangan tangan, berciuman, berpelukan, dan meraba/merangsang. Oleh karena itu, perlu dikembangkan media informasi tentang pentingnya kesehatan reproduksi dan faktor risiko perilaku seksual kepada remaja.

Kata Kunci: Faktor Internal; Perilaku Seksual Berisiko; Remaja

\section{ABSTRACT}

Background: Risky sexual behavior usually starts from fingering, holding hands, and kissing have been very worrying. There are some factors affected this sexual behavior, either internal or external.

Objective: Analyzed the internal factors associated with sexual risk behavior in adolescents in the Bengkulu province.

Methods: This quantitative research uses cross-sectional approach in 301 families who had adolescents aged 1024 years in Bengkulu Province. Data were analyzed descriptively (univariate) and bivariate using Chi Square.

Results: Risky sexual behavior in adolescents was began with holding hands (83,4\%), hugging (34,2\%), kissing lips $(15,6 \%)$, and touching/stimulating (3,3\%), mostly aged 15-19 years old with a high school education level, and the majority live in rural areas. Internal factor age is related to risky sexual behavior holding hands $(p=0,018)$, hugging $(p<0,001)$, and kissing $(p<0,001)$. Gender affected the behavior of hugging $(p<0,001)$, kissing $(p=0,010)$ and touching or stimulating $(p=0,008)$. Education had an effect on the behavior of holding hands $(p<$ $0,001)$ and kissing $(p=0,010)$, while the risk factor for residence was known to affect the behavior of kissing ( $p=$ $0,030)$.

Conclusion: Age, gender, education level and place of residence are risk factors for adolescent sexual behavior, especially holding hands, kissing, hugging, and touching/stimulating. Therefore, it is necessary to develop information media about the importance of adolescent reproductive health and risk factors for sexual behavior.

Keywords: Internal Factors; Risky Sexual Behavior; Adolescent 
PENDAHULUAN

Tahapan kehidupan remaja merupakan periode transisi dan terjadi berbagai perubahan unik yang membuat remaja merasa kurang paham dan bingung, di antaranya berfungsinya hormon seksual. Perubahan ini mendorong para remaja untuk melakukan berbagai jenis perilaku seksual (Taylorseehafer \& Rew, 2000).

Hasil survei diperoleh perilaku seksual berisiko remaja laki-laki lebih tinggi, yaitu 29,5\% dan remaja perempuan pernah melakukan meraba atau merangsang pasangannya sebesar $6,2 \%$. Lebih lanjut, sebanyak 48,1\% remaja lakilaki dan 29,3\% remaja perempuan pernah berciuman bibir, serta berpegangan tangan ketika berpacaran yang jumlahnya tidak berbeda antara remaja laki-laki dan perempuan $(79,6 \%$ dan $71,6 \%)$ (BKKBN, 2013).

Faktor-faktor yang berkontribusi terhadap munculnya perilaku seksual remaja dibedakan atas faktor internal remaja antara lain usia, jenis kelamin, struktur dan dinamika keluarga, pendidikan, pengetahuan dan sikap terhadap berbagai perilaku seksual (Joshi and Chauhan, 2011; Nursal, 2008). Menurut Etrawati et al. (2017), beberapa hal yang memengaruhi perilaku seksual berisiko pada remaja yakni teman bergaul dengan perilaku buruk, kepercayaan diri, kendali orangtua, dan gender.

Masa remaja sering diisi dengan pacaran. Gaya pacaran remaja sering kali terlihat tidak sehat. Hampir sepertiga (31\%) dari total remaja umur 10-24 tahun di Indonesia mengaku pernah berpacaran, dengan proporsi tertinggi pada remaja pria (BKKBN, 2019).

Usia pertama kali berpacaran pada remaja, baik pria, maupun wanita yang tinggal di perdesaan dan perkotaan adalah 15 tahun. Umur pacaran remaja wanita sangat dipengaruhi oleh tingkat pendidikan. Lebih rinci diperoleh remaja tamatan SD, umur pacaran pertama 12 tahun, sementara remaja pria yang berpendidikan SLTA, umur pacaran pertama di usia 15 tahun.

Apabila ditelusuri berdasarkan jenis kelamin, remaja pria lebih banyak dibandingkan dengan remaja wanita mengaku telah melakukan perilaku seksual seperti berpegangan tangan, berpelukan, ciuman bibir, dan meraba atau merangsang (BKKBN, 2019).

Perilaku seksual berisiko pada remaja wanita cenderung berbeda, yaitu lebih banyak dilakukan di perkotaan dibanding di pedesaan. Kecenderungan perilaku berpacaran remaja laki-laki yang berdomisili di perkotaan maupun di pedesaan adalah berpelukan, berciuman bibir, dan meraba (Li et al., 2013).

Meskipun persentasenya kecil, dijumpai 5\% remaja (20-24 tahun), 1\% remaja (5-19 tahun), bahkan pada remaja usia $10-14$ tahun $(0,1 \%)$ berpengalaman melakukan hubungan seksual. Remaja wanita yang memiliki pengetahuan seksual yang lebih baik diikuti sikap yang lebih terbuka (Li et al., 2013).

Penelitian di 17 kota besar di Indonesia terkait perilaku seksual remaja SMP dan SMA diperoleh sebanyak 97\% remaja pernah menonton pornografi, 93,7\% sudah tidak lagi perawan dan pernah melakukan aborsi (BKKBN, 2011). Perilaku ini di kalangan remaja sangat mengkhawatirkan sehingga diperlukan penelitian hubungan faktor dengan perilaku seksual berisiko pada remaja Provinsi Bengkulu.

\section{METODE}

Penelitian ini merupakan penelitian kuantitatif dengan pendekatan cross sectional study (desain potong lintang). Sumber data dalam penelitian ini adalah data sekunder berdasarkan Survei Kinerja dan Akuntabilitas Program (SKAP) remaja dan keluarga tahun 2019 di Provinsi Bengkulu.

Data penelitian ini adalah data sekunder bersumber dari Survei Kinerja 
dan Akuntabilitas Program (SKAP) Badan Kependudukan dan Keluarga Berencana Nasional (BKKBN) Tahun 2019 Provinsi Bengkulu yang terdiri dari SKAP Keluarga dan Remaja. Populasi penelitian terdiri atas pasangan orang tua dan remaja berusia 10-24 tahun di wilayah Provinsi Bengkulu yang berjumlah 856 pasang.

Sampel pada penelitian ini adalah ibu/ ayah yang mempunyai remaja dan data yang lengkap dan diolah sesuai dengan variabel penelitian, yaitu sebanyak 301 orang.

Variabel independen terdiri dari faktor internal remaja (umur, jenis kelamin, tingkat pendidikan dan tempat tinggal). Tingkat pendidikan dikategorikan rendah (belum sekolah, tamat SD), menengah (SLTP dan SLTA), tinggi (D1, D2, D3 dan PT).

Variabel dependen yaitu perilaku seksual berisiko yang dibedakan atas pegangan tangan, berpelukan, ciuman bibir, meraba/merangsang. Uji Chi Square digunakan untuk menganalisis hubungan variabel bebas dan terikat berskala ordinal.

\section{HASIL DAN PEMBAHASAN}

Survei Kinerja dan Akuntabilitas Program (SKAP) BKKBN Tahun 2019 Provinsi Bengkulu memberikan gambaran remaja yang telah berpacaran. Selanjutnya, remaja tersebut diberi pertanyaan lanjutan yaitu perilaku seksual apa yang dilakukan ketika berpacaran (baik pacar saat ini atau sebelumnya) dalam mengungkapkan rasa kasih sayang, yang mencakup berpegangan tangan, berpelukan, ciuman bibir, meraba/merangsang pada bagian tubuh yang sensitif, seperti payudara atau paha yang dilakukan oleh pacar (Tabel 1).
Tabel 1. Gambaran Perilaku Seksual Berisiko Remaja Umur 10-24 Tahun Provinsi Bengkulu

\begin{tabular}{clcc}
\hline No & Perilaku Seksual Berisiko & $\mathbf{n}$ & $\mathbf{\%}$ \\
\hline 1 & Pegangan Tangan & & \\
& a. Ya & 251 & 83,4 \\
& b. Tidak & 50 & 16,6 \\
2 & Berpelukan & & \\
& a. Ya & 103 & 34,2 \\
& b. Tidak & 198 & 65,8 \\
3 & Ciuman Bibir & 47 & 15,6 \\
& a. Ya & 254 & 84,4 \\
& b. Tidak & & \\
Meraba/Merangsang & 10 & 3,3 \\
& a. Ya & 291 & 96,7 \\
\hline & b. Tidak & \multicolumn{2}{c}{ bahwa } \\
& Tabel 1 mendeskripsikan & bahwa
\end{tabular}
remaja yang berpegangan tangan ketika pacaran sebesar $83,4 \%$, berpelukan $(34,2 \%)$, ciuman $(15,6 \%)$, dan meraba/ merangsang bagian tubuh yang sensitif (3,3\%). Angka ini memprihatinkan dan memerlukan intervensi yang tepat dan cepat. Kecenderungan remaja memiliki cara berpacaran yang semakin berani dan terbuka. Selain itu, diperoleh $1 \%$ pernah melakukan hubungan seksual pranikah pada remaja perempuan dan $5 \%$ remaja pada laki-laki berusia 15-24 tahun (BKKBN, 2013).

Salah satu perubahan yang berlangsung cepat saat remaja adalah perubahan seksual, yang ditandai dengan ketertarikan dengan lawan jenis pun semakin meningkat. Remaja menganggap berpacaran di masa ini merupakan bagian dari proses sosialisasi, menjalin keakraban dan memberi kesempatan untuk menciptakan hubungan yang spesial dan unik dengan lawan jenis, serta menjadi tahapan untuk melakukan eksperimen dan eksplorasi seksual. Perilaku seksual seperti kissing, necking, petting, dan intercourse berawal dilakukan masa pacaran (Setiawan \& Nurhidayah, 2008). 
Hubungan Faktor Internal dengan Perilaku Seksual Berisiko...

\begin{tabular}{|c|c|c|c|c|}
\hline No & Faktor Internal & $\mathbf{n}$ & $\%$ & Jumlah \\
\hline \multirow[t]{3}{*}{1} & Jenis Kelamin & & & \\
\hline & a. Perempuan & 121 & 40,2 & 301 \\
\hline & b. Laki-laki & 180 & 59,8 & \\
\hline \multirow[t]{4}{*}{2} & Umur (Tahun) & & & \\
\hline & a. $10-14$ & 21 & 7,0 & 301 \\
\hline & b. $15-19$ & 160 & 53,2 & \\
\hline & c. $20-24$ & 120 & 39,8 & \\
\hline \multirow[t]{7}{*}{3} & Tingkat Pendidikan & & & \\
\hline & a. Belum Sekolah & 2 & 0,7 & 301 \\
\hline & b. SD & 23 & 7,6 & \\
\hline & c. SLTP & 66 & 21,9 & \\
\hline & d. SLTA & 160 & 53,2 & \\
\hline & e. D1/D2/D3/akademik & 3 & 1,0 & \\
\hline & f. Perguruan Tinggi & 47 & 15,6 & \\
\hline \multirow[t]{3}{*}{4} & Tempat Tinggal & & & \\
\hline & a. Perkotaan & 112 & 37,2 & 301 \\
\hline & b. Pedesaan & 189 & 62,8 & \\
\hline
\end{tabular}

Tabel 2 mendeskripsikan bahwa berdasarkan faktor internal, sebagian besar remaja berjenis kelamin laki-laki $(59,8 \%)$, berusia remaja menengah $(53,2 \%)$, tingkat pendidikan SLTA $(53,2 \%)$, dan mayoritas $(62,8 \%)$ tinggal di pedesaan. Sebagian besar remaja perkotaan maupun pedesaan menganggap pacaran lumrah.

Terdapat remaja yang beranggapan bahwa masa remaja identik dengan masa berpacaran, dan kalau tidak berpacaran, remaja akan dianggap ketinggalan zaman dan kurang pergaulan. Faktor lain yang mempengaruhi perilaku pacaran berisiko adalah melihat teman yang sedang berpacaran sehingga mulai mencoba untuk pacaran (Umaroh, 2017).

Tabel 3 menunjukkan bahwa ada keterkaitan faktor internal umur dengan pegangan tangan (nilai p 0,018). Kelompok remaja awal (10-14 tahun) cenderung tidak melakukan pegangan tangan saat berpacaran. Remaja tengah dan akhir cenderung melakukan pegangan tangan.

Berbagai perubahan baik secara fisik maupun psikis pada fase persiapan menjadi dewasa dialami remaja. Fakta menunjukkan bahwa remaja menganggap dirinya sudah mulai dewasa dan mandiri, serta boleh melakukan segala hal tanpa mempertimbangkan usia dalam berperilaku seksual berisiko. Usia tidak dapat dijadikan sebagai patokan terhadap perilaku pacaran, baik perilaku pacaran berisiko maupun tidak (Masatu et al., 2009).

Tabel 2. Faktor Internal Remaja Provinsi Bengkulu

\begin{tabular}{|c|c|c|c|c|c|c|c|c|c|c|}
\hline No & $\begin{array}{c}\text { Faktor } \\
\text { Internal } \\
\text { Remaja }\end{array}$ & Kategori & $\begin{array}{l}\text { Pegangan } \\
\text { Tangan }\end{array}$ & $\begin{array}{c}p- \\
\text { value }\end{array}$ & Berpelukan & $\begin{array}{c}p- \\
\text { value }\end{array}$ & $\underset{\text { Bibir }}{\text { Ciuman }}$ & $\begin{array}{c}p- \\
\text { value }\end{array}$ & $\begin{array}{c}\text { Meraba/ } \\
\text { Merangs } \\
\text { ang }\end{array}$ & $\begin{array}{c}p- \\
\text { value }\end{array}$ \\
\hline \multirow{2}{*}{1.} & \multirow{2}{*}{$\begin{array}{l}\text { Jenis } \\
\text { Kelamin }\end{array}$} & Perem- & $97(80,2 \%)$ & \multirow[t]{2}{*}{0,220} & $22(18,25 \%)$ & \multirow[t]{2}{*}{$<0,001$} & $9(7,4 \%)$ & \multirow[t]{2}{*}{0,010} & $2(1,7 \%)$ & \multirow[t]{2}{*}{0,010} \\
\hline & & Laki-laki & $154(85,6 \%)$ & & $81(45 \%)$ & & $38(21,1 \%)$ & & $10(6,5 \%)$ & \\
\hline \multirow[t]{3}{*}{2.} & Umur & $10-14$ & $13(41,9 \%)$ & \multirow{3}{*}{0,018} & $1(4,8 \%)$ & \multirow[t]{3}{*}{$<0,001$} & $2(9,5 \%)$ & \multirow[t]{3}{*}{$<0,001$} & $3(14,3 \%)$ & \multirow[t]{3}{*}{0,610} \\
\hline & & $15-19$ & $133(83,6 \%)$ & & $41(25,8 \%)$ & & $13(8,2 \%)$ & & $5(3,1 \%)$ & \\
\hline & & $20-24$ & $105(86,8 \%)$ & & $61(50,4 \%)$ & & $34(28,1 \%)$ & & $5(4,15 \%)$ & \\
\hline \multirow{3}{*}{3.} & Tingkat & Rendah & $20(83,3 \%)$ & \multirow{3}{*}{0,960} & $8(33,3 \%)$ & \multirow[t]{3}{*}{0,010} & $3(12,5 \%)$ & \multirow{3}{*}{0,010} & $1(4,2 \%)$ & \multirow[t]{3}{*}{0,360} \\
\hline & \multirow[t]{2}{*}{ Pendidikan } & $\begin{array}{l}\text { Menen- } \\
\text { gah }\end{array}$ & $190(83,7 \%)$ & & $69(30,4 \%)$ & & $29(12,8 \%)$ & & $9(4,0 \%)$ & \\
\hline & & Tinggi & $41(82,0 \%)$ & & $26(52,0 \%)$ & & $15(30,0 \%)$ & & $2(4,0 \%)$ & \\
\hline \multirow{2}{*}{4.} & \multirow{2}{*}{$\begin{array}{l}\text { Tempat } \\
\text { Tinggal }\end{array}$} & Perkota- & $95(84,0 \%)$ & \multirow[t]{2}{*}{0,610} & $42(37,5 \%)$ & \multirow[t]{2}{*}{0,360} & $24(21,4 \%)$ & \multirow[t]{2}{*}{0,030} & $1(0,9 \%)$ & \multirow[t]{2}{*}{0,070} \\
\hline & & $\begin{array}{l}\text { Pedesa- } \\
\text { an }\end{array}$ & $156(82,5 \%)$ & & $61(32,2 \%)$ & & $23(12,2 \%)$ & & $9(4,8 \%)$ & \\
\hline
\end{tabular}


Usia remaja adalah usia yang rawan untuk menggali berbagai pengenalan dan petualangan akan hal-hal baru sebagai persiapan awal yang akan digunakan pada periode dewasa. Namun, banyak remaja yang kurang dapat mengendalikan diri sehingga beberapa pengalaman yang tampaknya menyenangkan justru dapat menjerumuskan.

Akibat emosi penuh gejolak dan masih labil, tidak sedikit remaja terjerumus dalam perilaku seksual yang salah. Konsekuensi yang harus diterima akibat perilaku remaja yang melakukan hubungan seksual pranikah, yaitu kehamilan yang tidak dikehendaki (unwanted pregnancy) (Li et al., 2013; Sari \& Rokhanawati, 2018).

Tabel 3 menunjukkan bahwa faktor internal, karakteristik remaja meliputi jenis kelamin ( $p$-value $<0,001)$, umur remaja $(p$-value $<0,001)$, dan tingkat pendidikan remaja ( $p$-value 0,010$)$ memiliki hubungan yang signifikan dengan perilaku seksual berisiko berpelukan. Lebih lanjut, remaja yang telah pernah berhubungan seksual pranikah sebanyak $2 \%$ pada remaja pria dan $1 \%$ pada wanita.

Hal ini sejalan dengan penelitian Joshi and Chauhan (2011) yang mengatakan bahwa remaja laki-laki yang belum menikah cenderung lebih aktif secara seksual dibanding remaja perempuan. Bahkan remaja laki-laki lebih menyetujui hubungan perilaku seksual berisiko dan memiliki banyak kesempatan untuk terlibat dalam hubungan seksual (Joshi \& Chauhan, 2011).

Remaja yang berusia $14-16$ tahun akan mengalami dorongan seksual yang meningkatkan kemampuan menarik lawan jenis dan berdampak pada terjadinya perilaku seksual berisiko (Soeroso, 2016). Selain itu, tingkat pendidikan remaja yang rendah menghambat perkembangan sikap terutama dalam hal menerima setiap informasi sehingga remaja melakukan perilaku seksual berisiko berpelukan dalam pacaran (Li et al., 2013).

Tabel 3 menunjukkan jenis kelamin, umur, tingkat pendidikan dan tempat tinggal remaja memiliki hubungan signifikan dengan perilaku seksual berisiko khususnya ciuman bibir, masingmasing nilai $\mathrm{p}$ adalah jenis kelamin $(p-$ value 0,01$)$, umur remaja ( $p$-value $<0,001)$, tingkat pendidikan (p-value 0,01), dan tempat tinggal ( $p$-value 0,03$)$. Remaja yang tidak melakukan ciuman bibir cenderung berjenis kelamin perempuan dan berumur lebih muda (remaja awal).

Namun, remaja bertempat tinggal di perkotaan lebih cenderung melakukan berciuman bibir. Hal ini mungkin karena masyarakat di perkotaan cenderung mengadopsi gaya hidup kebarat-baratan sehingga mereka lebih banyak melakukan perilaku seksual berisiko (Sari \& Rokhanawati, 2018).

Tabel 3 menjelaskan bahwa jenis kelamin memiliki hubungan nyata terhadap perilaku seksual berisiko meraba/ merangsang ( $p$-value 0,008). Remaja yang telah matang secara seksual (berusia 2024 tahun), lebih ingin tahu terkait seksual juga mempunyai keinginan untuk berinteraksi dan memikat lawan jenisnya.

Remaja yang berusia 20-24 tahun merasa sudah dewasa dan sangat rentan dengan berbagai pengalaman yang dapat mempengaruhi usia ini melakukan perilaku seksual pranikah. Hal inilah yang mendorong usia ini lebih serius dengan lawan jenis (berpacaran). Rasa aman (feelings of security) bila berdekatan dengan pacarnya dapat menimbulkan suatu keintiman seksual pada diri remaja yang mendorong remaja melakukan perilaku seksual yang berisiko (Setiawan \& Nurhidayah, 2008).

Penelitian di China mengemukakan bahwa pengembangan pendidikan seksual di sekolah sangat penting agar remaja tidak memperoleh informasi yang tidak tepat dari teman sebayanya karena secara psikologis usia remaja lebih mendengarkan dan mudah dipengaruhi 
teman sebaya ( $\mathrm{Li}$ et al., 2013). Selain itu, remaja lebih percaya diri melakukan perilaku seksual apabila teman/ sahabatnya sebagai sumber informasinya tentang seks (Stevens et al., 2017).

Selain informasi yang diperoleh dari tenaga kesehatan, peran orang tua juga sangat penting dalam menyampaikan informasi seputar permasalahan kesehatan reproduksi dan seksualitas kepada remaja (Rusmilawaty et al., 2016). Komunikasi reguler antara orang tua dan anak remaja tentang seksual dan kesehatan reproduksi berkontribusi dalam pencegahan pernikahan dini dan kehamilan yang tidak diinginkan (Mekonen et al., 2018).

\section{PENUTUP}

Faktor internal remaja (umur) berkaitan dengan perilaku seksual berisiko khususnya berpegangan tangan. Perilaku seksual berisiko khususnya berpelukan berhubungan nyata dengan jenis kelamin, umur, tingkat pendidikan. Remaja lakilaki lebih berisiko untuk melakukan perilaku seksual berisiko khususnya meraba/merangsang. Oleh karena itu, pencegahan perilaku seksual yang berisiko di kalangan remaja sangat penting dilakukan.

\section{UCAPAN TERIMA KASIH}

Ucapan terima kasih disampaikan kepada Badan Kependudukan dan Keluarga Berencana Nasional (BKKBN) Provinsi Bengkulu yang telah menyediakan data dan mendanai penelitian ini.

\section{DAFTAR PUSTAKA}

BKKBN. (2011). Profil Hasil Pendataan Keluarga Tahun 2011. Badan Kependudukan dan Keluarga Berencana Nasional Direktorat Pelaporan dan Statistik.

BKKBN. (2013). Pemantauan Pasangan Usia Subur Melalui Mini Survei Indonesia.

BKKBN. (2019). Survei Kinerja dan Akuntabilitas Program KKBPK
(SKAP) Remaja. In Puslitbang KB dan KS Badan Kependudukan dan Keluarga Berencana Nasional (Vol. 53, Issue 9). https://doi.org/10.1017/ CBO9781107415324.004

Etrawati, F., Martha, E., \& Damayanti, R. (2017). Psychosocial Determinants of Risky Sexual Behavior among Senior High School Students in Merauke District. Kesmas: Jurnal Kesehatan Masyarakat Nasional (National Public Health Journal), 11(3), 127-132. https:// doi.org/10.21109/KESMAS.V11I3.1163

Joshi, B., \& Chauhan, S. (2011). Determinants of Youth Sexual Behaviour: Program Implications for India. Eastern Journal of Medicine, 16(2), 113-121.

Li, S., Chen, R., Cao, Y., Li, J., Zuo, D., \& Yan, H. (2013). Sexual Knowledge, Attitudes and Practices of Female Undergraduate Students in Wuhan, China: The Only-Child versus Students with Siblings. PLOS ONE, 8(9). $\quad$ https://doi.org/10.1371/ journal.pone.0073797

Masatu, M. C., Kazaura, M. R., Ndeki, S., \& Mwampambe, R. (2009). Predictors of Risky Sexual Behavior among Adolescents in Tanzania. AIDS Behav, 13, 94-99. https://doi.org/10.1007/ s10461-007-9292-x

Mekonen, M. T., Dagnew, H. A., Yimam, T. A., Yimam, H. N., \& Reta, M. A. (2018). Adolescent-parent communication on sexual and reproductive health issues and associated factors among high school students in Woldia town, northeastern Ethiopia. Pan African Medical Journal, 31, 1-15. https://doi.org/10.11604/ pamj.2018.31.35.13801

Nursal, D. G. (2008). Faktor-Faktor Yang Berhubungan Dengan Perilaku Seksual Murid SMU Negeri Di Kota Padang Tahun 2007. Jurnal Kesehatan Masyarakat Andalas, 2(2), 175. https:// doi.org/10.24893/jkma.2.2.175180.2008 
Rusmilawaty, R., Yuniarti, Y., \& Tunggal, T. (2016). Communication of Parents, Sexual Content Intake and Teenage Sexual Behavior at Senior High School in Banjarmasin City. Kesmas: Jurnal Kesehatan Masyarakat Nasional Vol., 10(3), 113-119.

Sari, D. E., \& Rokhanawati, D. (2018). The Correlation Between Age of First Dating and Sexual Behavior of Adolescents and Young Adults in Indonesia. Journal of Health Technology Assessment in Midwifery, 1(1), 23-28. https://doi.org/10.31101/jhtam.441

Setiawan, R., \& Nurhidayah, S. (2008). Pengaruh pacaran terhadap perilaku seks pranikah. Jurnal Soul, 1(2), 59-72.

Soeroso, S. (2016). Masalah Kesehatan Remaja. Sari Pediatri, 3(3), 189. https:// doi.org/10.14238/SP3.3.2001.189-97
Stevens, R., Gilliard-Matthews, S., Dunaev, J., Todhunter-Reid, A., Brawner, B., \& Stewart, J. (2017). Social Media Use and Sexual Risk Reduction Behavior among Minority Youth: Seeking Safe Sex Information. Nursing Research, 66(5), 368-377. https://doi.org/10.1097/ NNR.0000000000000237

Taylor-seehafer, M., \& Rew, L. (2000). Risky Sexual Behavior Among Adolescent Women. JSPN, 5(1), 15-25.

Umaroh, A. K., Kusumawati, Y., \& Kasjono, H. S. (2017). Hubungan Antara Faktor Internal Dan Faktor Eksternal Dengan Perilaku Seksual Pranikah Remaja Di Indonesia. Jurnal Kesehatan Masyarakat Andalas, 10(1), 65. https://doi.org/10.24893/jkma.10.1.6575.2015 